\title{
Contemporary experience with surgical treatment of aortic valve disease in children
}

\author{
Muhammad S. Khan, MD, ${ }^{\text {a,b }}$ Andres X. Samayoa, MD, ${ }^{\text {a,b }}$ Diane W. Chen, BS, ${ }^{b}$ \\ Christopher J. Petit, MD, ${ }^{\mathrm{c}}$ and Charles D. Fraser, Jr, MD ${ }^{\mathrm{a}, \mathrm{b}}$
}

\begin{abstract}
Objectives: Surgical treatment of aortic valve (AoV) disease in childhood involves complex decisions particularly in very small patients. There is no consensus regarding the optimum surgical option. The objective of this review was to analyze a contemporary experience of AoV surgery in a large children's hospital.
\end{abstract}

\begin{abstract}
Methods: A retrospective review of children (aged $\leq 18$ years) undergoing AoV repair or replacement from June 1995 to December 2011 was carried out.

Results: A total of 285 AoV operations (97 repairs, 188 replacements) were performed on 241 patients. Hospital survival for repair was $98 \%$ and for replacements was $97 \%$. At follow-up of repairs, there were $16(17 \%)$ reoperations and $3(3 \%)$ late deaths. Follow-up of AoV replacements demonstrated 31 (16\%) reoperations (homograft 27, autograft 3, mechanical 1) and $8(4 \%)$ late deaths (homograft 5, autograft 2, mechanical 1). Freedom from reintervention or death (FRD) was found to be lower in repairs for infants $(P=.048)$ and truncal valves $(P<.05)$. For AoV replacements, infants and patients who had concomitant CHD or homografts $(P<.0001)$ had lower FRD. Cox regression analysis for AoV replacements identified infants and homograft root replacements at a higher risk for death/reoperation.
\end{abstract}

Conclusions: AoV repairs and replacements were generally found to be associated with low death and reoperation rates at long-term follow-up. Infants had a lower freedom from reintervention or death after either an AoV repair or replacement, although truncal valve repairs and AoV replacement in patients with concomitant CHD were associated with lower valve survival. Among the valve options, homograft root replacement had a higher risk of death/reoperation and lowest freedom from reintervention or death. ( $\mathrm{J}$ Thorac Cardiovasc Surg 2013;146:512-21)

Surgical treatment of aortic valve (AoV) disease in children involves complex decisions with the prospect of impact on decades of life. Although a variety of treatment strategies exist, essentially no option can be construed as a definitively durable long-term solution if one considers the potential of a normal lifespan. In most children undergoing surgery for AoV disease, reoperation is an unavoidable outcome. Currently there is no consensus on the best treatment for AoV disease in the pediatric patient.

There appears to be a wide variation in practice patterns relative to treatment of $\mathrm{AoV}$ disease in children. ${ }^{1,2}$ This observation is logically associated with the lack of a truly "ideal" replacement option for the AoV. Theoretically, an

From the Michael E. DeBakey Department of Surgery, ${ }^{a}$ Baylor College of Medicine,

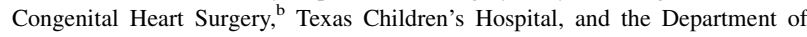
Pediatric Cardiology, ${ }^{\mathrm{c}}$ Baylor College of Medicine and Texas Children's Hospital, Houston, Tex.

Disclosures: Authors have nothing to disclose with regard to commercial support.

Read at the 38th Annual Meeting of The Western Thoracic Surgical Association, Maui, Hawaii, June 27-30, 2012.

Received for publication June 25, 2012; revisions received Dec 8, 2012; accepted for publication April 18, 2013.

Address for reprints: Charles D. Fraser, Jr, MD, Baylor College of Medicine, Texas Children's Hospital, 6621 Fannin St, WT19345H, Houston, TX 77030 (E-mail: charlesf@bcm.edu).

$0022-5223 / \$ 36.00$

Copyright (c) 2013 by The American Association for Thoracic Surgery

http://dx.doi.org/10.1016/j.jtcvs.2013.04.014 ideal pediatric valve substitute offers indefinite durability, does not elicit a host immune response, offers a hemodynamic profile comparable with that of a normal native $\mathrm{AoV}$, does not require anticoagulation, is easy and safe to implant, and perhaps most important, has the potential for appropriate somatic growth in synchrony with the patient. Given the widely perceived lack of a perfect valve replacement option in childhood, most pediatric cardiac surgeons believe native AoV repair is a viable palliative option for appropriate patients. ${ }^{3-5}$ Although AoV repair is safe and in many series reported to offer acceptable intermediate term valve function, reoperation remains a certainty. ${ }^{6,7}$

The surgeon who counsels a family about AoV replacement options faces the daunting task of attempting to assimilate incomplete data from relatively small series if one considers the aggregate pediatric experience in comparison with that in adult cardiac surgery. Options include the broad categories of mechanical prostheses, human cadaveric replacement (homograft root), pulmonary autograft root (Ross procedure), and various bioprostheses. This may present a confusing and even frustrating conundrum for the family. Although definite institutional biases exist, there are limited objective long-term data available to aid in this process.

At our own institution, we have observed a wide variety of treatment options being offered to children with AoV 


\section{Abbreviations and Acronyms \\ ACEi/ = angiotensin-converting enzyme \\ ARBS inhibitor/angiotensin receptor blocker \\ $\mathrm{AoV}=$ aortic valve \\ CHD = congenital heart disease \\ FRD $=$ freedom from reintervention or death}

disease. As such, the objective of this study was to analyze the contemporary outcomes of children undergoing AoV surgery in a large children's hospital.

\section{METHODS}

This was a retrospective review of patients who have undergone repair or a replacement of the AoV at Texas Children's Hospital from June 1995 to December 2011. Patients who were aged $\leq 18$ years at surgery were included. Institutional review board approval from the Baylor College of Medicine was obtained for conducting this study.

\section{Data Collection}

Data were collected on study participants from electronic databases (Congenital Heart Surgery database, Pediatric Cardiology/Echo databases) and clinical records. To provide the most complete follow-up, we directly contacted families of patients not recently seen at our institution and conducted telephone interviews. Long-term subject follow-up (after hospital discharge) was $85 \%$ complete for this cohort. Accepted guidelines for reporting morbidity and mortality after cardiac valve interventions were used. $^{8}$

The entire cohort was divided into 2 primary study groups: AoV repair or replacement.

AoV repair. Subjects who underwent repair were subclassified into 3 clinical categories: isolated AoV disease, AoV disease associated with significant other congenital heart disease (CHD), and truncus arteriosus with valve dysfunction. Repairs were additionally analyzed on the basis of the surgical procedure performed and classified as simple or complex. Complex repairs included leaflet resuspension, elevation, augmentation, extensive leaflet debridement requiring reconstruction, resection and subcommissural leaflet plication, annuloplasty, valve-sparing root repair, and Trusler repair. All other repairs were classified as simple. Any repair associated with concomitant subaortic membrane resection was excluded from the cohort.

AoV replacement. Subjects undergoing AoV replacement were also subclassified according to choice of valve substitute. Groups included patients undergoing pulmonary autograft root replacement (Ross procedure), homograft root replacement, mechanical/composite valve (as isolated valve or Bentall procedure), and bioprosthetic valves. Patients undergoing concomitant root-enlarging procedures were included.

\section{Variables}

Variables analyzed include gender, age, and weight at surgery, number of previous AoV operations, number of previous interventional aortic valvuloplasties, diagnostic criteria (described earlier), valve repair type, type of valve replacement, time receiving ventilatory support, duration of stay in the intensive care unit and hospital, postoperative complications, and discharge status. Preoperative and last follow-up echocardiographic measurements of severity of valve dysfunction, left ventricular end-diastolic and end-systolic dimensions, Z-scores (number of standard deviations above or below mean expected dimension for body surface area), shortening fraction Z-scores as a measure of left ventricular function, reoperations, and mortality were also reported.

\section{DATA ANALYSIS}

Continuous variables were reported as median with minimums and maximums or means with standard deviations. Frequencies were calculated for categorical variables with percentages. Replacement and repair failures and mortality were modeled as time-dependent events using the KaplanMeier and life table methods and reported as freedom from reintervention on the AoV or death (FRD). Any reintervention other than the AoV, for example, the right-sided reinterventions after a Ross procedure, were not a part of this analysis. Factors associated with treatment failures were analyzed using the multivariable Cox regression models separately for AoV repairs and replacements. All data were analyzed using IBM SPSS version 19 (IBM, Armonk, NY).

\section{RESULTS}

A total of 241 children underwent $285 \mathrm{AoV}$ operations during the study period. The median age at first operation was 6.8 years (1 day-18 years) and $87(36 \%)$ patients were female. The median weight at first operation was $21.7 \mathrm{~kg}(2-110.2 \mathrm{~kg})$.

\section{AoV Repairs}

Ninety-two patients (36 [39\%] female) underwent 97 AoV repairs at a median age and weight of 2.6 years (1-18 years) and $11.6 \mathrm{~kg}(2.1-110.2 \mathrm{~kg})$, respectively. The majority $(74,76 \%)$ of patients undergoing AoV repairs had concomitant CHD (including 22 [23\%] patients with truncal valve insufficiency) and $23(23 \%)$ patients had isolated AoV disease. The majority $(80,82 \%)$ of patients who underwent AoV repair had no prior AoV intervention (catheter or surgical). Forty-one ( $42 \%$ ) patients underwent simple AoV repair and $56(58 \%)$ had complex AoV repair (Table 1). Indications for AoV repair included insufficiency in $46(47 \%)$, stenosis in $17(18 \%)$, and combined insufficiency and stenosis in $31(32 \%)$, whereas $3(3 \%)$ patients had dilation of the aortic root with no valve dysfunction. In total, $8(8 \%)$ patients had aortic root dilation requiring valve-sparing root repair. (For echocardiographic severity of valve dysfunction, refer to Table 2.)

\section{Postoperative Course}

Postoperative complications were infrequent in patients undergoing AoV repair and included bleeding requiring postoperative transfusion or surgical exploration in $4(4 \%)$ patients, nosocomial infections in $8(8 \%)$ patients, renal insufficiency in $3(3 \%)$ patients, chylothorax in $1(1 \%)$ patient, and heart and respiratory failure postoperatively secondary to multiple complex defects and repairs in $1(1 \%)$ patient. Two patients had immediate failure of repair (within 24 hours) requiring AoV replacement owing to stenosis (1) or insufficiency (1). There were 2 hospital deaths: 1 patient 
TABLE 1. Characteristics of pediatric patients that underwent AoV repair

\begin{tabular}{|c|c|c|c|}
\hline Characteristics & Simple repair $(n=41)$ & Complex repair $(\mathbf{n}=\mathbf{5 6})$ & $P$ value \\
\hline Median age (range) & $7.5 \mathrm{mo}(1 \mathrm{~d}-16.8 \mathrm{y})$ & 4.3 y $(5 \mathrm{~d}-18 \mathrm{y})$ & .037 \\
\hline Female $(\%)$ & $15(37)$ & $24(43)$ & .675 \\
\hline Median weight (kg, range) & $6.8(2.4-93)$ & $20.1(2.1-110.2)$ & .033 \\
\hline \multicolumn{4}{|l|}{ Diagnostic groups } \\
\hline AoV disease only $(\%)$ & $11(27)$ & $12(22)$ & $<.0001$ \\
\hline AoV disease with other CHD (\%) & $30(73)$ & $22(39)$ & \\
\hline Truncal valve $(\%)$ & $0(0)$ & $22(39)$ & \\
\hline Previous BAV (\%) & $6(15)$ & $3(5)$ & .161 \\
\hline Previous AoV interventions (\%) & $7(17)$ & $11(20)$ & .797 \\
\hline Mean CPB time \pm SD (min) & $166 \pm 52$ & $215 \pm 79$ & .001 \\
\hline Mean crossclamp time $\pm \mathrm{SD}(\mathrm{min})$ & $104 \pm 41$ & $137 \pm 62$ & .005 \\
\hline Median ventilator time (d, range) & $1(0-10)$ & $1(0-14)$ & .658 \\
\hline Median ICU length of stay (d, range) & $4(1-12)$ & $3(0-9)$ & .027 \\
\hline Median hospital length of stay (d, range) & $8(3-194)$ & $6(1-141)$ & .094 \\
\hline Thirty-day survival (\%) & $40(98)$ & $55(98)$ & 1.0 \\
\hline
\end{tabular}

$P$ values in bold are significant. $A o V$, Aortic valve; $C H D$, congenital heart disease; $B A V$, aortic valvuloplasty; $C P B$, cardiopulmonary bypass; $S D$, standard deviation; $I C U$, intensive care unit.

with truncus arteriosus had pulmonary hypertension and hemodynamic instability after repair and 1 infant with severe aortic stenosis and mitral valve stenosis/insufficiency with discontinuous pulmonary arteries died after a prolonged hospital course involving multiple reoperations for recurrent aortic stenosis. The patient required a left ventricular assist device, had pulmonary hypertension, and had a number of infections leading to death. Hospital survival after AoV repair was $98 \%$ (Table 3 ).

\section{Late Complications}

At a mean follow-up time of $3.7 \pm 3.8$ years ( 8 days- 15.4 years); there were $16(17 \%)$ reoperations and 3 late deaths. Complications at long-term follow-up for the 76 surviving patients without further AoV intervention included subacute bacterial endocarditis in $1(1 \%)$, supraventricular tachycardia in $1(1 \%)$, hypertensive cardiomyopathy in 1 $(1 \%)$, recurrence of insufficiency in $38(50 \%)$, stenosis in
$14(18 \%)$, and combined insufficiency and stenosis in 18 $(24 \%)$. For severity of valve dysfunction based on echocardiographic, data refer to Table 2.

\section{Risk Factors for Repair Failure and FRD}

Factors significantly associated with repair failure (reoperation or death) on univariate analysis were infant age group $(P=.05)$, complex repair type $(P=.05)$, and the diagnosis of truncus arteriosus $(P=.001)$. However, multivariable Cox regression analysis showed no significant difference among these risk factors. On Kaplan-Meier analysis, infants $(P=.048)$ and truncal valves were found to have the lowest FRD $(P<.05)$ (Figure $1, A-C)$.

\section{AoV Replacement}

One hundred sixty-two children (57 [35.2\%] female) underwent 188 valve replacements at a median age of

TABLE 2. Preoperative and follow-up AoV dysfunction in repairs and replacements

\begin{tabular}{|c|c|c|c|c|}
\hline \multirow[b]{2}{*}{ Echocardiographic findings } & \multicolumn{2}{|c|}{ AoV repairs } & \multicolumn{2}{|c|}{ AoV replacements } \\
\hline & Preoperative $(\mathbf{n}=97)$ & Follow-up* $(n=64)$ & Preoperative $(n=188)$ & Follow-up* $(n=143)$ \\
\hline \multicolumn{5}{|l|}{ Stenosis $\dagger$} \\
\hline Severe & $12(12 \%)$ & - & $27(14 \%)$ & $5(3 \%)$ \\
\hline Moderate & $14(14 \%)$ & $6(9 \%)$ & $41(22 \%)$ & $9(6 \%)$ \\
\hline Mild & $21(22 \%)$ & $26(41 \%)$ & $41(22 \%)$ & $15(10 \%)$ \\
\hline Trivial & $1(1 \%)$ & - & - & $8(6 \%)$ \\
\hline \multicolumn{5}{|l|}{ Insufficiency $\dagger$} \\
\hline Severe & $18(19 \%)$ & $2(3 \%)$ & $58(31 \%)$ & $10(7 \%)$ \\
\hline Moderate & $32(33 \%)$ & $14(22 \%)$ & $52(28 \%)$ & $15(10 \%)$ \\
\hline Mild & $20(21 \%)$ & $27(42 \%)$ & $29(15 \%)$ & $55(38 \%)$ \\
\hline Trivial & $7(7 \%)$ & $14(22 \%)$ & $8(4 \%)$ & $65(45 \%)$ \\
\hline Mean LVEDD \pm SD & $1.50 \pm 2.7$ & $0.48 \pm 1.9$ & $1.94 \pm 2.9$ & $-0.32 \pm 1.6$ \\
\hline Mean LVESD \pm SD & $0.69 \pm 2.8$ & $0.04 \pm 1.73$ & $2.61 \pm 1.0$ & $-0.63 \pm 1.9$ \\
\hline Mean $\mathrm{SF} \pm \mathrm{SD}$ & $0.46 \pm 2.7$ & $0.51 \pm 1.68$ & $0.92 \pm 3.1$ & $0.56 \pm 2.4$ \\
\hline
\end{tabular}

$A o V$, Aortic valve; $L V E D D$, left ventricular end-diastolic dimension; $L V E S D$, left ventricular end-systolic dimension; $S F$, shortening fraction; $S D$, standard deviation. *Includes patients alive without further reintervention. †Includes combined insufficiency and stenosis. 
TABLE 3. Characteristics of pediatric patients that underwent AoV replacement

\begin{tabular}{|c|c|c|c|c|c|}
\hline Characteristics & Autograft $(n=68)$ & Homograft $(n=74)$ & Mechanical $(\mathbf{n}=36)$ & Bioprosthetic $(n=10)$ & $P$ value* \\
\hline Median age (range) & 5.9 y $(6 \mathrm{~d}-17 \mathrm{y})$ & 4.9 y $(4 \mathrm{~d}-16.5 \mathrm{y})$ & 14 y $(2.1-17.8$ y) & 15.9 y $(5.5-18$ y) & $<.0001$ \\
\hline Females $(\%)$ & $21(31)$ & $27(37)$ & $15(42)$ & $3(30)$ & .594 \\
\hline Median weight ( $\mathrm{kg}$, range) & $21.0(3.4-96)$ & $17.8(2-96.3)$ & $48.9(10-109.3)$ & $63.0(20-89.1)$ & $<.0001$ \\
\hline \multicolumn{6}{|l|}{ Diagnostic groups } \\
\hline AoV disease only ( $\%)$ & $47(69)$ & $26(35)$ & $12(33)$ & $10(100)$ & .168 \\
\hline AoV disease with other CHD (\%) & $21(31)$ & $41(55)$ & $18(50)$ & - & \\
\hline Truncal valve $(\%)$ & 一 & $7(10)$ & $6(17)$ & - & \\
\hline Previous BAV $(\%)$ & $29(43)$ & $20(27)$ & $6(17)$ & $3(30)$ & .067 \\
\hline Previous AoV interventions ( $\%)$ & $45(66)$ & $29(39)$ & $19(53)$ & $5(50)$ & 1.0 \\
\hline Mean valve size (mm, range) & - & $15(7-26)$ & $22(17-29)$ & $22(19-27)$ & $<.0001$ \\
\hline Mean $\mathrm{CPB}$ time $\pm \mathrm{SD}(\min )$ & $288 \pm 75$ & $262 \pm 69$ & $229 \pm 77$ & $238 \pm 87$ & .001 \\
\hline Mean crossclamp time $\pm \mathrm{SD}(\min )$ & $191 \pm 40$ & $189 \pm 44$ & $163 \pm 54$ & $174 \pm 65$ & .002 \\
\hline Mean ventilator time (d, range) & $1(0-67)$ & $1(0-35)$ & $1(0-8)$ & $0(0-1)$ & .01 \\
\hline Median ICU length of stay (d, range) & $3(1-67)$ & $3(0-35)$ & $3(1-23)$ & $2(1-7)$ & .336 \\
\hline Median hospital length of stay (d, range) & $6(3-98)$ & $6(0-58)$ & $7(4-29)$ & $7(3-12)$ & .066 \\
\hline Thirty-day survival $(\%)$ & $67(99)$ & $71(96)$ & $36(100)$ & $10(100)$ & .44 \\
\hline
\end{tabular}

$P$ values in bold are significant. $A o V$, Aortic valve; $C H D$, congenital heart disease; $B A V$, aortic valvuloplasty; $C P B$, cardiopulmonary bypass; $S D$, standard deviation; $I C U$, intensive care unit. *Comparison between valves for younger children (autograft and homografts) versus older children (mechanical and bioprosthetic).

8.3 years (4 days-18 years) and median weight of $25.4 \mathrm{~kg}$ $(2-109.3 \mathrm{~kg})$. Indications for replacements included combined AoV insufficiency and stenosis in 93 (49\%), insufficiency only in $54(29 \%)$, and stenosis only in $16(9 \%)$ patients. Valves used included aortic homograft in 74 (39\%), pulmonary autograft (as a complete root replacement) in $68(36 \%)$, mechanical valves in $36(19 \%)$ (St Jude Medical 21, St Jude Medical with composite root 15 [St Jude Medical, Inc, St Paul, Minn]), and bioprosthetic valves in 10 (6\%) (Medtronic Freestyle 6 [Medtronic, Inc, St Paul, Minn], St Jude Medical Epic 3, St Jude Medical Biocor 1). An aortic root-enlarging (Konno or Manougian) procedure was concomitantly performed in $27(14 \%)$ patients (16 with the Ross procedure, 9 with homografts, 2 with mechanical valve replacements) (Table 3 ).

\section{Postoperative Course}

Hospital complications included arrhythmias requiring treatment in $5(3 \%)$ (2 complete atrioventricular block, 2 supraventricular tachycardia, 1 atrial ectopic tachycardia), bleeding requiring reexploration in $3(2 \%)$, and stroke, deep vein thrombosis, and vocal cord paralysis in 1 each $(<1 \%)$. There were 6 hospital deaths, 4 in patients who received a homograft $\mathrm{AoV}$ and 2 in patients who underwent a Ross procedure. The 4 deaths in homograft recipients included 3 in infants (2 Shone complex, 1 interrupted aortic arch) and 1 in a neonate (Shone complex). Two of these patients had pulmonary hypertension, and 2 were hemodynamically unstable requiring support with an extracorporeal membrane oxygenator. The 2 autograft recipients who died included an infant and a neonate both with a diagnosis of Shone complex. Causes included pulmonary hypertension and hemodynamic instability requiring support with an extracorporeal membrane oxygenator. The overall hospital survival of patients undergoing AoV replacement was $97 \%$.

\section{Late Complications}

The mean duration of follow-up for the valve replacement cohort was $5.0 \pm 4.0$ years ( 0 days- 15 years) (Table 2 ). Complications according to valve types were as follows:

Homograft valves. Seventy-four homografts were implanted in 65 patients. At a mean follow-up of $4.0 \pm 4.0$ years (0 days-13.6 years) there were 27 (36\%) reoperations and 5 late deaths. At reoperation, 12 of the 27 received a pulmonary autograft, 8 had a homograft of a larger size, and 7 had a mechanical valve. Complications in patients who were alive without reoperation at follow-up included left ventricular dysfunction requiring an implantable defibrillator in $1(2 \%)$, ventricular tachycardia requiring a pacemaker in $1(2 \%)$, and syncope in $1(2 \%)$. Medications at last follow-up included aspirin in $23(55 \%)$, beta-blockers in 8 $(19 \%)$, angiotensin-converting enzyme inhibitor/angiotensin receptor blocker (ACEi/ARBS) in $4(9 \%)$, furosemide in $3(7 \%)$, calcium-channel blockers in $2(5 \%)$, and coumadin, digoxin, enoxaparin, and dipyridamole in 1 each $(2 \%)$. Autograft valves. Of the 68 patients undergoing a Ross procedure, $3(4 \%)$ had a reoperation on the neo-AoV ( 2 mechanical valves, 1 valve-sparing root repair). There were 2 late deaths during a mean follow-up of $6.7 \pm 4.2$ years (4 days- 15 years). Of the patients who were alive without further AoV reintervention, 16 (26\%) had right-sided conduit reintervention, $1(2 \%)$ stroke secondary to antiphospholipid antibody syndrome, and $1(2 \%)$ had a pacemaker for heart block. Medications at last follow-up included aspirin in $29(47 \%)$, ACEi/ARBS in $18(29 \%)$, beta-blockers in $14(23 \%)$, coumadin and digoxin in $2(3 \%)$ each, and furosemide and thiazide diuretic in $1(2 \%)$ each. 

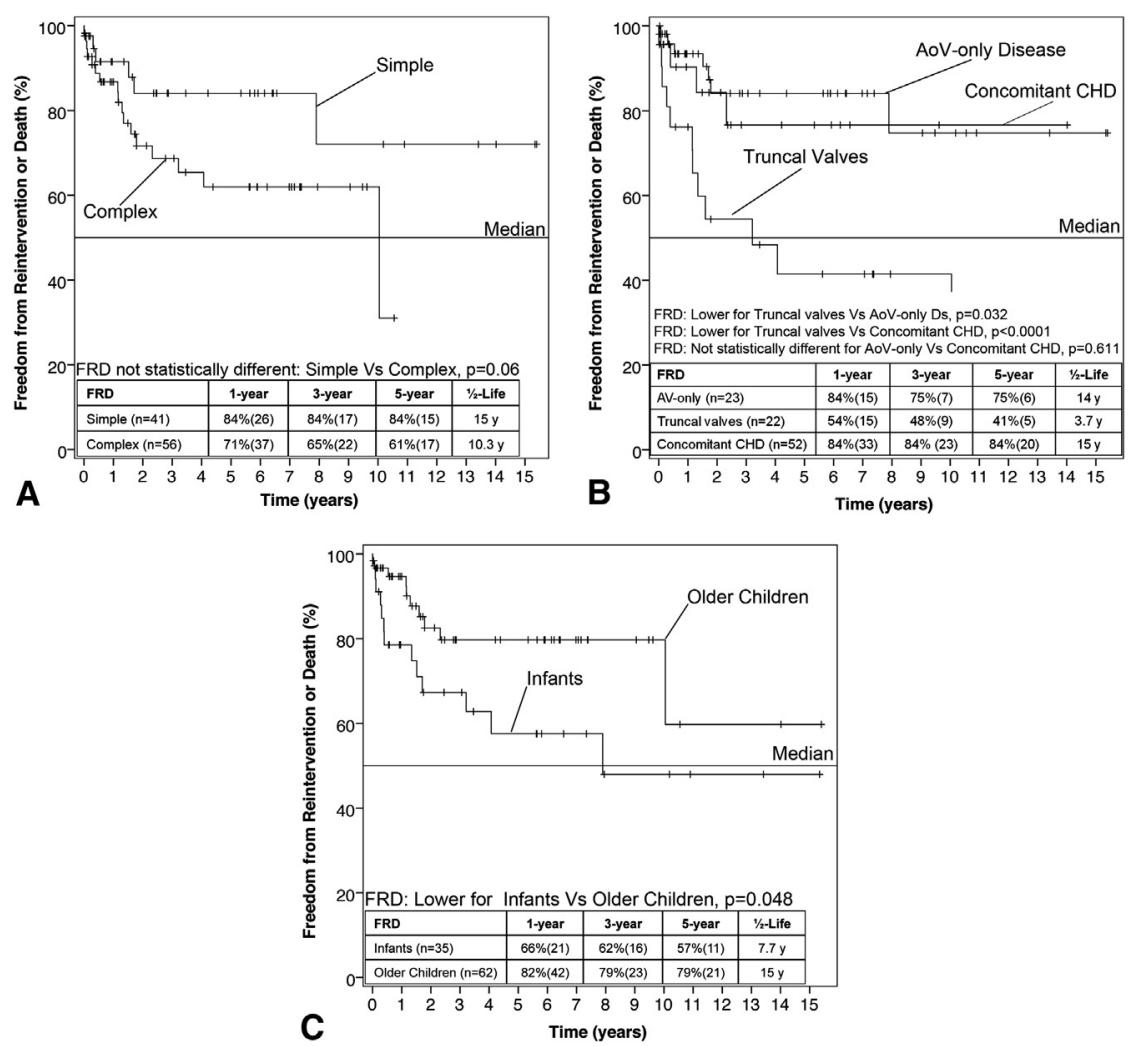

FIGURE 1. FRD for simple and complex AoV repairs (A), for all AoV repairs according to diagnostic group (B), and for all AoV repairs according to age group (C). FRD, Freedom from reintervention or death; $A o V(A V)$, aortic valve; $C H D$, congenital heart disease; $D s$, disease.

Mechanical/composite valves. There were 36 mechanical valves implanted in 36 patients. At a mean follow-up of 4.6 \pm 3.3 years ( 9 days-13.3 years), there was $1(3 \%)$ reoperation with an autograft and $1(3 \%)$ late death. The complications noted at the last follow-up were valve thrombus in $1(3 \%)$, atrial ectopic tachycardia in $1(3 \%)$, stroke in 1 $(3 \%)$, and syncope in $1(3 \%)$. Medications at last followup included coumadin in $30(88 \%)$, beta-blockers in 9 $(26 \%)$, ACEi and digoxin in $7(21 \%)$ each, aspirin and furosemide in $6(18 \%)$ each, and dipyridamole in $4(12 \%)$.

Bioprosthetic valves. Of the 10 patients who had a bioprosthetic valve implanted, none had a reoperation and no deaths were reported. The follow-up was complete for these patients with a mean follow-up of $3.0 \pm 1.2$ years $(7$ months-4. 4 years). Complication was reported in 1 patient (severe valve insufficiency after an episode of endocarditis) awaiting reoperation. Medication at last follow-up included, aspirin in $4(40 \%)$ and beta-blockers in $3(30 \%)$.

\section{Children With Multiple Valve Replacements}

Of the children in the AoV replacement cohort, 23 had a second valve replacement at age $\leq 18$ years after a mean follow-up time of $3.2 \pm 2.4$ years. Twenty-two of the 23 children had a homograft root as the primary valve replacement and 1 had a Ross procedure. The second valve option at reoperation for the 22 homograft valve replacement failures were the Ross procedure in 10 patients, a second homograft in 9 patients, and a mechanical valve in 3 patients. Of the 9 patients who had a second homograft root replacement, 3 required a third valve replacement ( 2 had a Ross procedure, 1 had a mechanical valve) at age $\leq 18$ years. There was 1 death at long-term follow-up reported in the patients who had multiple valve replacements in childhood and that in a patient who had an autograft primary valve replacement followed by a mechanical valve.

\section{Risk Factors for Replacement Failures and FRD}

On univariate analysis, replacement failures (reoperation or death) were significantly more frequent in infants $(P<.0001)$, in patients without a history of surgical or percutaneous valve interventions $(P=.003)$, and in those with concomitant CHD $(P<.0001)$. Replacement failures were associated with homograft valve replacements $(P<.0001)$. Multivariable Cox regression analysis of these factors showed that infants (hazard ratio, $9.1 ; P<.0001$ ) and individuals undergoing a homograft valve replacement (hazard ratio, $15.5 ; P<.0001$ ) were more likely to have a valve replacement failure. On Kaplan-Meier analysis, homograft valve replacements were associated with a lower FRD than all other types of valve replacements $(P \leq .05)$. Infants 

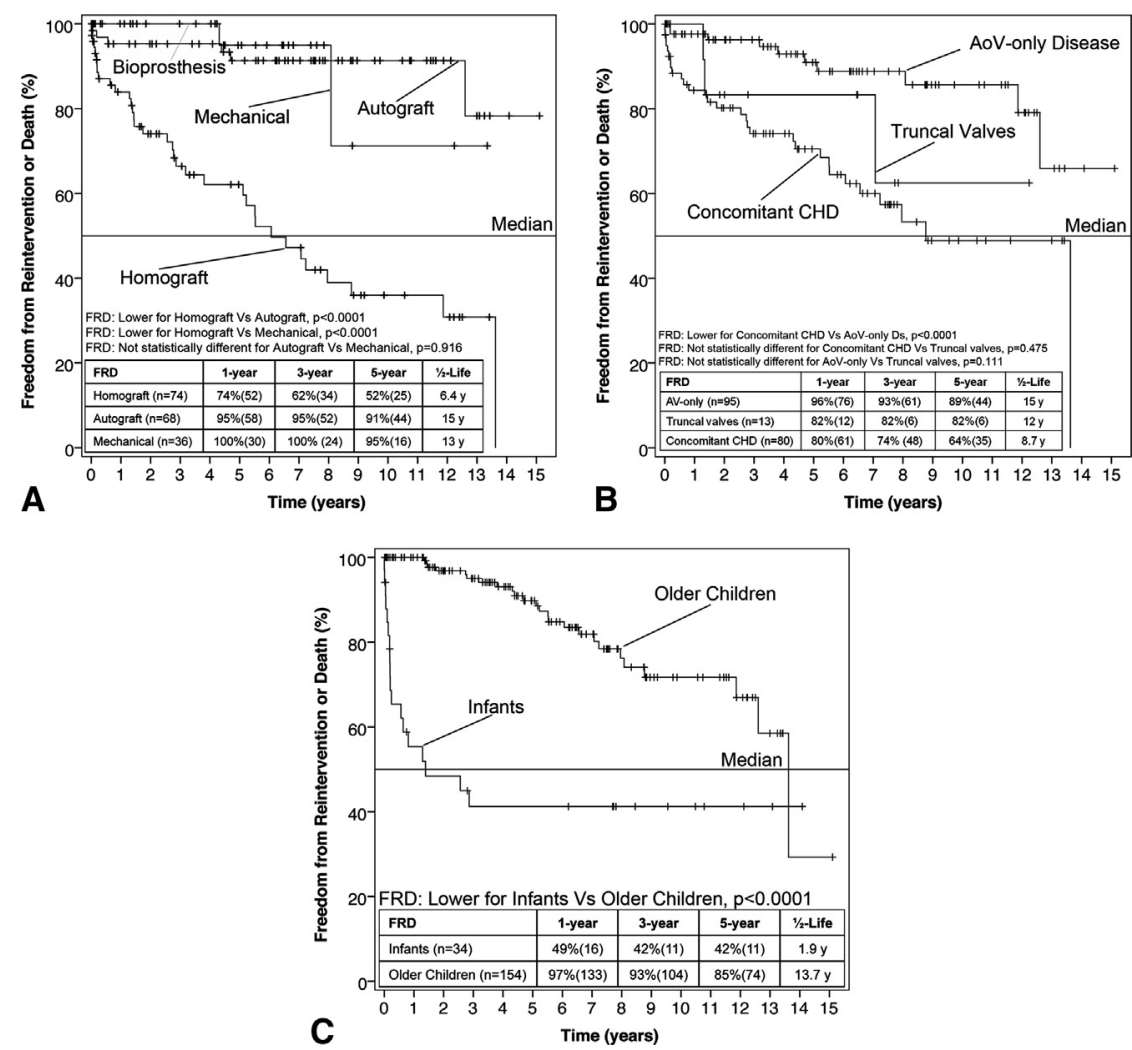

FIGURE 2. FRD for different types of AoV replacements (A), for all AoV replacements according to diagnostic group (B), and for all AoV replacements according to age group (C). $F R D$, Freedom from reintervention or death; $A o V(A V)$, aortic valve; $C H D$, congenital heart disease; $D s$, disease.

were found to be a risk group for FRD $(P<.0001)$. Also, patients with concomitant CHD had significantly lower FRD than those with dysfunction of AoV only $(P<.0001)$ (Figure 2, $A-C$ ).

\section{DISCUSSION}

This study underscores the diversity of the population of children with AoV disease requiring surgical intervention. Although acceptable outcomes have been achieved using a wide variety of surgical options, no single approach offers immunity from the potential for reoperation or long-term complication.

As in other pediatric centers, our institutional preference has been to repair the native $\mathrm{AoV}$ whenever possible. This option appears to benefit the patient by minimizing the need for anticoagulation, preserving the potential for somatic growth, and preserving the opportunity to use other replacement options in the future. In our experience, reoperation for early or late failure of a repaired AoV has been associated with low risk of mortality $(5 \%)$. These results are consistent with published AoV repair series in pediatric patients. ${ }^{4,9,10}$ The rate of reoperation is also similar to previous study, with recurrence of dysfunction after repair being primarily dependent on the valvular structure. ${ }^{11}$ We classified major AoV reconstructions including truncal valve repairs and valve-sparing root repairs in the complex AoV repair category. It is encouraging that outcomes for this group were not demonstrably different from the simple repair group. For an algorithm of decision making in children requiring aortic valve surgery, refer to Figure 3.

AoV replacement in this study was associated with excellent survival and low morbidity. Overall, valve replacement outcomes of our patients were comparable with published pediatric literature. ${ }^{12,13}$ Patients more likely to have failure of replacement included the patients that had other significant CHD. This group included a variety of diagnoses with patients frequently undergoing multiple concomitant intracardiac repairs along with AoV replacement. Interestingly, patients undergoing truncal valve replacement were found to have a superior FRD rate to others in CHD group. This is in contradistinction to published series of truncal valve repairs and replacements in which long-term survivals have been noted to be compromised. ${ }^{14}$

Of the valve replacement options applied to small patients (children in whom adult-sized prostheses cannot be used), the Ross procedure appears to be the most durable. ${ }^{15,16}$ Although not always possible owing to anatomic defects and clearly a more technically demanding procedure, several large studies including our own have shown excellent midterm and long-term results. ${ }^{17-20}$ Our current 


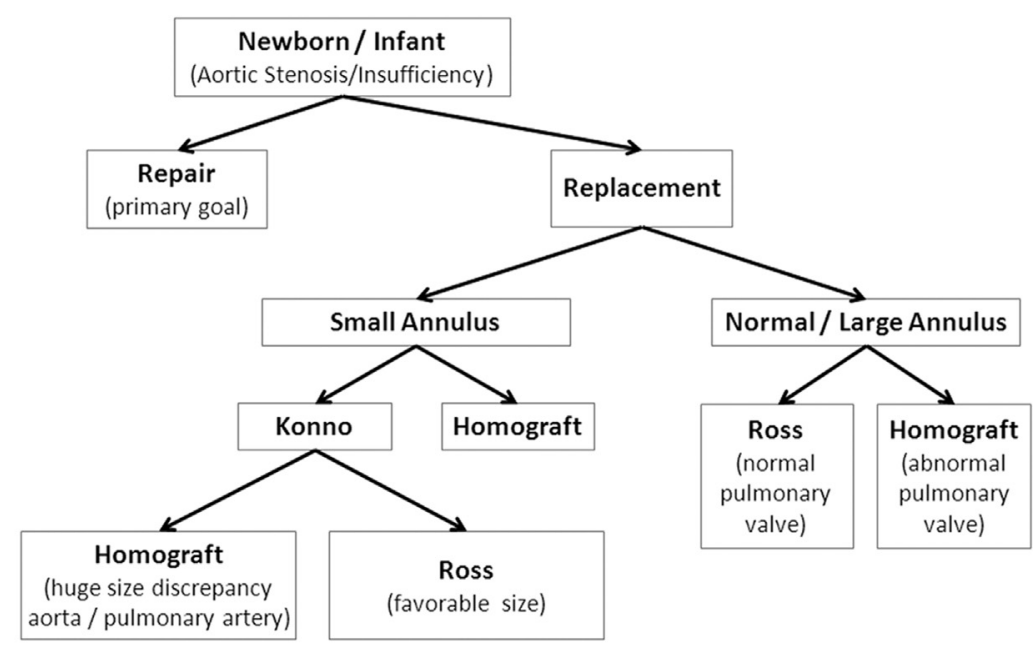

A

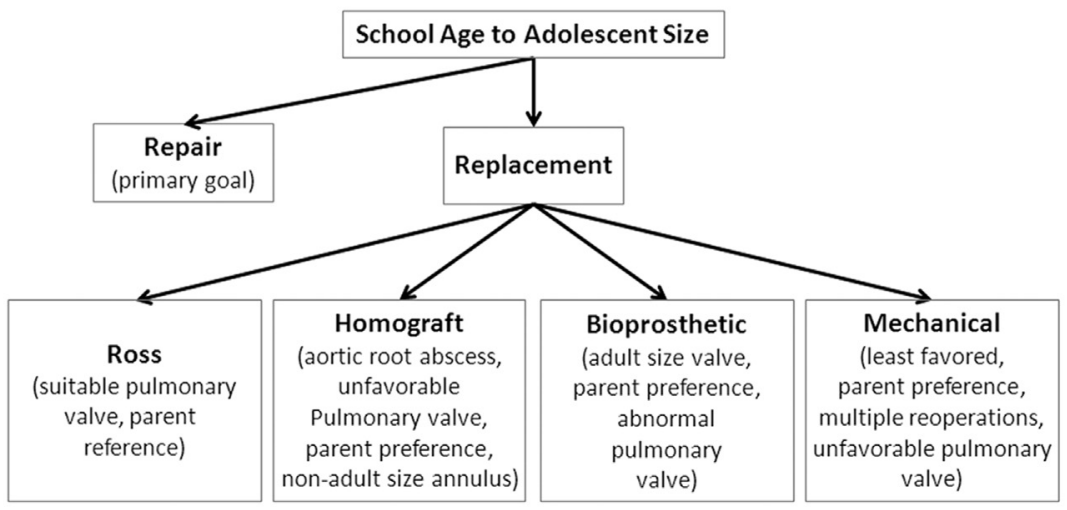

B

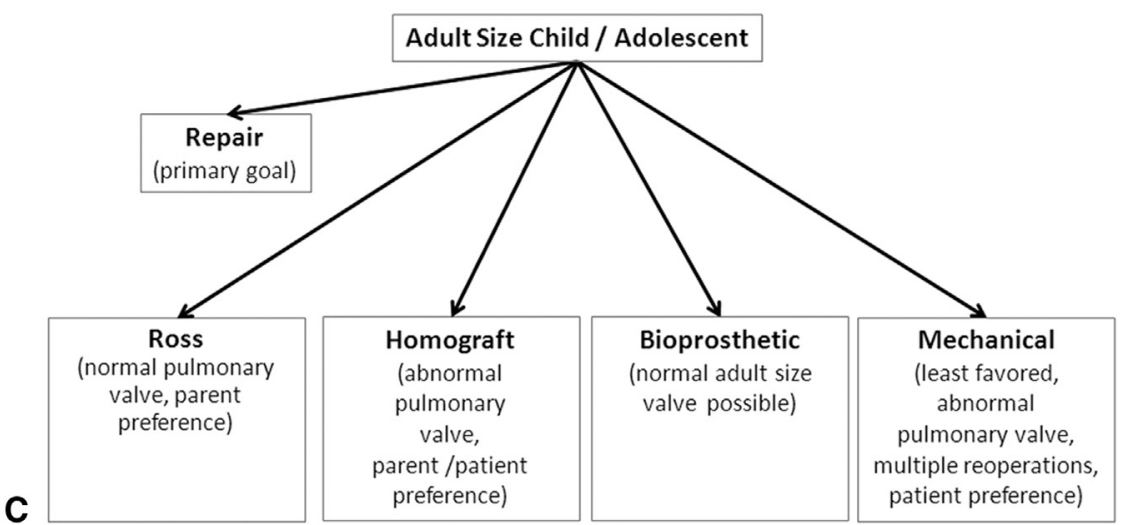

FIGURE 3. Algorithm at Texas Children's Hospital for aortic valve surgery for newborns/infants (A), school age to adolescent-sized children (B), and adolescents and adult-sized children (C).

study confirms excellent outcomes of patients with low rates of reoperation and death. We have adopted a selective approach to the Ross procedure in smaller patients and have often "staged" smaller children with an intervening homograft before the index Ross procedure with good results. Reoperation for the right-sided valved conduit remains an important concern for this group of patients.
Aortic homograft valves were frequently implanted in this series. This option has been favored for some of our smaller patients and in patients whose anatomy precludes a Ross procedure. A recent randomized controlled trial in adults demonstrated improved survival, freedom from reoperation, and quality of life for autograft versus the homograft root replacement. ${ }^{21}$ These data along with our own 
imply a more aggressive stance with regard to the application of the Ross procedure in childhood may be justifiable.

Mechanical valves may be considered a durable option for the treatment of AoV disease in children. ${ }^{20}$ Limitations in the pediatric population are magnified in the very young and include somatic outgrowth and the challenges of managing anticoagulation. We observed $100 \%$ short-term survival and 2 failures at long-term follow-up. Of the 5 patients less than 5 years of age at time of mechanical AoV replacement in our series, all are doing well at follow-up on anticoagulation. Fifty percent of our patients had CHD and $50 \%$ of the patients had undergone a previous surgical or catheter AoV intervention. Both factors appear to have no impact on outcomes as described by others. ${ }^{22,23}$ Our results with the use of mechanical valves confirm that this valve can be reliably used in the pediatric population if anticoagulation can be appropriately managed. In our cohort, $9 \%$ of patients who were on anticoagulation had a complication at long-term follow-up.

There are very limited data concerning the application of bioprosthetic valves in the pediatric population, with most studies focused on the use of this option in late teenage years. $^{24,25}$ Previous studies have implied that use of bioprosthetic valves in pediatric years is a risk factor for valve failure. ${ }^{12,25}$ Our experience, although quite limited, suggests the newer generations of bioprostheses may be more durable, particularly when larger sizes can be used to obviate the needs of somatic growth. At present followup, there have been no reoperations or mortality in our series, although 1 patient has evidence of valve deterioration (after endocarditis) and will require reoperation. The smallest patient in our series was a 5-year-old who received a complete porcine root (Medtronic Freestyle). Overall, our experience with the use of bioprosthetic valves is encouraging and we promote the application of this option in older children.

The current study confirms that infants undergoing AoV repair or a replacement represent a higher risk group. These data are consistent with findings as reported by Karamlou and associates, ${ }^{12}$ in which both low age and weight were reported to be associated with replacement failure. With 69 infant operations including 34 replacements (19 homografts and 15 Ross procedures), we report the largest series of infants from a single institution. Despite improvements in management for this high-risk group compared with the older children, there is still room for progress. It is noteworthy that the majority of smaller patients have severe, lifethreatening disease that puts them at a higher risk for morbidity and mortality. In our replacement cohort, all of the early deaths were in infants.

Study limitations include the inherent limitations of a retrospective design. Patients included had diverse anatomy and underwent a variety of treatments during the follow-up period. Indications and timing of surgery and the operative technique may also have varied over the study period. Details of the right-sided conduit for the Ross procedure concomitantly performed were not collected for this study. Management of patients after operation has also changed considerably over the 16-year period of this study, the effect of which was not separately evaluated. Last, a comprehensive set of variables were collected to study the different surgical options; however, the unmeasured covariates may have also affected the results. Nonetheless, this study represents the reality of practice in a large, quaternary children's hospital and emphasizes the imperfect nature of all treatment options for children with AoV disease.

In conclusion, AoV repair and replacement are satisfactory surgical options associated with acceptable overall survival and low morbidity. Surgical strategy should include not only the limitations and risks of all options, but increasingly, the informed opinion of the family. Complex and simple repairs have similarly good long-term outcomes. The Ross procedure, as well as use of mechanical and bioprosthetic valves, is associated with excellent results whereas right-sided intervention with the Ross procedure remains a concern. Although aortic homografts should remain part of the treatment armamentarium, caution concerning longterm durability should be exercised in selecting this option. Without doubt, there is much room for improvement in the development of more idealized valve substitute options for children.

\section{References}

1. Vahanian A, Baumgartner H, Bax J, Butchart E, Dion R, Filippatos G, et al Guidelines on the management of valvular heart disease: The Task Force on the Management of Valvular Heart Disease of the European Society of Cardiology. Eur Heart J. 2007;28:230-68.

2. Bonow RO, Carabello BA, Kanu C, de Leon AC Jr, Faxon DP, Freed MD, et al. ACC/AHA 2006 guidelines for the management of patients with valvular heart disease. Circulation. 2006;114:e84-231.

3. Pozzi M, Quarti A, Colaneri M, Oggianu A, Baldinelli A, Colonna PL. Valve repair in congenital aortic valve abnormalities. Interact Cardiovasc Thorac Surg. 2010;10:587-91.

4. Alsoufi B, Karamlou T, Bradley T, Williams WG, Van Arsdell GS, Coles JG, et al. Short and midterm results of aortic valve cusp extension in the treatment of children with congenital aortic valve disease. Ann Thorac Surg. 2006;82: 1292-9; discussion 1300.

5. Aicher D, Fries R, Rodionycheva S, Schmidt K, Langer F, Schäfers HJ. Aortic valve repair leads to a low incidence of valve-related complications. Eur J Cardiothorac Surg. 2010;37:127-32.

6. Baram S, McCrindle BW, Han RK, Benson LN, Freedom RM, Nykanen DG. Outcomes of uncomplicated aortic valve stenosis presenting in infants. Am Heart J. 2003;145:1063-70.

7. Brown JW, Ruzmetov M, Vijay P, Rodefeld MD, Turrentine MW. Surgery for aortic stenosis in children: a 40-year experience. Ann Thorac Surg. 2003;76:1398-411.

8. Akins CW, Miller DC, Turina MI, Kouchoukos NT, Blackstone EH, Grunkemeier GL, et al. Guidelines for reporting mortality and morbidity after cardiac valve interventions. J Thorac Cardiovasc Surg. 2008;135:732-8.

9. Brown JW, Rodefeld MD, Ruzmetov M, Eltayeb O, Yurdakok O, Turrentine MW. Surgical valvuloplasty versus balloon aortic dilation for congenital aortic stenosis: are evidence-based outcomes relevant? Ann Thorac Surg. 2012;94:146-53; discussion 153-5.

10. d'Udekem Y, Siddiqui J, Seaman CS, Konstantinov IE, Galati JC, Cheung MM, et al. Long-term results of a strategy of aortic valve repair in the pediatric population. J Thorac Cardiovasc Surg. 2013;145:461-7; discussion 467-9. 
11. Aicher D, Kunihara T, Abou Issa O, Brittner B, Gräber S, Schäfers HJ. Valve configuration determines long-term results after repair of the bicuspid aortic valve. Circulation. 2011;123:178-85.

12. Karamlou T, Jang K, Williams WG, Caldarone CA, Van Arsdell G, Coles JG, et al. Outcomes and associated risk factors for aortic valve replacement in 160 children: a competing-risks analysis. Circulation. 2005;112:3462-9.

13. Coskun KO, Popov AF, Tirilomis T, Schmitto JD, Coskun ST, Hinz J, et al. Aortic valve surgery in congenital heart disease: a single-center experience. Artif Organs. 2010;34:E85-90.

14. Russell HM, Pasquali SK, Jacobs JP, Jacobs ML, O’Brien SM, Mavroudis C, et al. Outcomes of repair of common arterial trunk with truncal valve surgery: a review of the Society of Thoracic Surgeons Congenital Heart Surgery database. Ann Thorac Surg. 2012;93:164-9; discussion 169.

15. Al-Halees Z, Pieters F, Qadoura F, Shahid M, Al-Amri M, Al-Fadley F. The Ross procedure is the procedure of choice for congenital aortic valve disease. J Thorac Cardiovasc Surg. 2002;123:437-41; discussion 441-2.

16. Shinkawa T, Bove EL, Hirsch JC, Devaney EJ, Ohye RG. Intermediate-term results of the Ross procedure in neonates and infants. Ann Thorac Surg. 2010;89: 1827-32; discussion 1832.

17. Clark JB, Pauliks LB, Rogerson A, Kunselman AR, Myers JL. The Ross operation in children and young adults: a fifteen-year, single-institution experience. Ann Thorac Surg. 2011;91:1936-41; discussion 1941-2.

18. Takkenberg JJ, Klieverik LM, Schoof PH, van Suylen RJ, van Herwerden LA, Zondervan PE, et al. The Ross procedure: a systematic review and meta-analysis. Circulation. 2009;119:222-8.

19. Morales DL, Carberry KE, Balentine C, Heinle JS, McKenzie ED, Fraser CD Jr. Selective application of the pediatric Ross procedure minimizes autograft failure. Congen Heart Dis. 2008;3:404-10.

20. Alsoufi B, Al-Halees Z, Manlhiot C, McCrindle BW, Al-Ahmadi M, Sallehuddin A, et al. Mechanical valves versus the Ross procedure for aortic valve replacement in children: propensity-adjusted comparison of long-term outcomes. J Thorac Cardiovasc Surg. 2009;137:362-70.e9.

21. El-Hamamsy I, Eryigit Z, Stevens LM, Sarang Z, George R, Clark L, et al. Longterm outcomes after autograft versus homograft aortic root replacement in adults with aortic valve disease: a randomised controlled trial. Lancet. 2010;376:524-31.

22. Popov AF, Coskun KO, Tirilomis T, Schmitto JD, Hinz J, Kriebel T, et al. Mechanical aortic valve replacement in children and adolescents after previous repair of congenital heart disease. Artif Organs. 2009;33:915-21.

23. Masuda M, Kado H, Ando Y, Shiose A, Nakano T, Fukae K, et al. Intermediateterm results after the aortic valve replacement using bileaflet mechanical prosthetic valve in children. Eur J Cardiothorac Surg. 2008;34:42-7.

24. Alsoufi B, Manlhiot C, McCrindle BW, Canver CC, Sallehuddin A, Al-Oufi S, et al. Aortic and mitral valve replacement in children: is there any role for biologic and bioprosthetic substitutes? Eur J Cardiothorac Surg. 2009;36: 84-90; discussion 90

25. Fann JI, Miller DC, Moore KA, Mitchell RS, Oyer PE, Stinson EB, et al. Twentyyear clinical experience with porcine bioprostheses. Ann Thorac Surg. 1996;62: 1301-11; discussion 1311-2.

\section{Discussion}

Dr Tara Karamlou (San Francisco, Calif). Thank you, Dr Khan. Dr Khan and colleagues are to be commended for tackling the problem of determining the "ideal" AoV intervention for AoV disease in pediatric patients. The study was well conceived and executed, represents one of the largest series of infants undergoing intervention, and Dr Khan provided the manuscript to me well in advance of the meeting. The $98 \%$ survival is commendable and the $85 \%$ follow-up of the cohort, which included outreach to patients not followed up at their institution, is also excellent. The study is a retrospective review of $285 \mathrm{AoV}$ repairs and replacements in 241 patients over a 16 -year period. The authors report that for valve repair, infants and those with truncus arteriosus had higher risk for the primary composite end point of death and reoperation. Similarly, risk factors for the composite end point for valve replacement cases included infants, those with concomitant CHD, and those having homograft valves.
The good points regarding the study notwithstanding, the results elucidated are not novel inasmuch as several prior publications have shown that patients of younger age, those receiving homograft valves, and those with concomitant CHD including truncus arteriosus to have worse outcomes than other pediatric patients undergoing AoV intervention.

With this in mind, I have several questions for the authors.

The authors stated in their conclusions, and some of these are conclusions from the manuscript and not necessarily from the presentation, that patients having homograft valve replacements have lower freedom from their composite end point of reoperation and death. Patients having homografts, however, were significantly younger and had significantly smaller valves implanted, often 15 mm versus $22 \mathrm{~mm}$ for the other valve types, compared with other replacement patients. Furthermore, the authors stated that they had adopted a policy to "stage" smaller children with an intervening homograft valve before performing an index Ross operation. In other words, replacing the homograft was really a fait accompli. Finally, since era was not mentioned as a covariate, and considering the fact that the study circumscribed a broad historical period, was the policy of staging patients adopted on the basis of a prior analysis of patients undergoing the Ross operation from your own institution?

In other words, my question is, based on these confounders, do the authors believe that their study may be unfairly biased against homograft valves?

Dr Khan. Thank you, Dr Karamlou, for your thoughtful comments. We agree with your observation that much of what we present in this paper is not novel; however, many of those data you refer to represent aggregate multi-institutional series and we believe that it is important for individual institutions to carefully monitor their own experience as this is the end point between the patient and the heart team.

Regarding the questions, we purposely elected to study a time frame representative of a consistent management strategy and team. Although multiple surgeons were involved, the approach to smaller patients, particularly those in whom there is a very large size discrepancy between the pulmonary valve and native or reconstructed aortic root, has remained constant. Our thinking has been that using a small homograft as a primary reconstructive method with the expectation, as you correctly note, of an early reoperation on the root allows a more durable application of the Ross procedure. This has been borne out in our experience with a low risk of subsequent Ross procedure after primary homograft root replacement. That being said, given our current data analysis, we are likely to adopt at our institution a somewhat more liberal application of the Ross procedure in smaller children.

Dr Karamlou. I was confused by the statement made in the manuscript that complex valve repairs fared no worse than simple valve repairs. First, the complex repair group included all of the truncal valve interventions, which were identified as a risk factor for reoperation and death, and the Kaplan-Meier plot showed a 5-year freedom from your composite end point of $84 \%$ for simple repairs compared with a 5-year freedom of $61 \%$ for complex repairs. Although the $P$ value reported is .07, the curves are impressively different. Considering the difference in follow-up favoring the simple group, do the authors really believe that there is no 
clinically important difference among these groups? In other words, is this really a type 2 error?

Dr Khan. We agree that this might be actually clinically significant difference, but statistically it was not significant. That is what we reported, and we made a slight change in the final manuscript.

Dr Karamlou. Can the authors elaborate on their institutional approach to patients with truncal valve dysfunction? Considering the considerably worse outcomes in this group, at what age and at what level of dysfunction do they recommend intervening on the valve?

Dr Khan. Regarding our approach to truncal valves, we have chosen to be aggressive with repair even at that time of the primary operation. As you know, acute significant truncal insufficiency is an important risk factor for patients undergoing truncus repair. As such, we have liberally approached various truncal valve repair methods including rudimentary sinus resection, leaflet suspension and extension, and bicuspidization. For irreparable truncal valves, we agree that mechanical valve replacement is a useful option but have elected to defer this option in most cases until a suitably large valve can be placed to limit the potential of somatic outgrowth. We also favor minimizing the obligate challenges associated with managing warfarin in children.

Dr Ross Ungerleider (Winston-Salem, NC). Very nice. It is a wonderful series. I am sitting here trying to wrap my brain around it and so I hope my questions are not naïve.

First of all, you started out your presentation with this case history of a woman with multiple reinterventions but not death. I am puzzled why you would combine freedom from death or reintervention in your graphs because they are very different outcomes. As you go about revising this manuscript, you might find it useful to separate those two things out because death is such a different outcome. It may be the eventual outcome of multiple reinterventions. Can you comment about why you chose to put those two together? I think they might obscure some of the conclusions that you are trying to make.

Dr Khan. Thank you for your question. The primary reason that we chose to include death and reintervention together is that we were trying to show the worst case scenario from a valve replacement. The most difficult question to answer is when a parent asks, "How long will the valve survive?" We wanted to present the whole picture to parents.

Dr Ungerleider. Another question is that your incidence of right ventricle-pulmonary artery conduit replacement in the patients with autografts was high at $26 \%$. Could you comment on that? Do you think that some of that was related to patients outgrowing their conduit or did you have a conduit deterioration rate that was about a quarter of the patients? I am curious what conduit you are using in those cases.

Dr Khan. I would ask Dr Fraser to comment on the type of conduit that we use.

Dr Fraser. Dr Ungerleider, thanks for your comments. We used almost exclusively homografts, but I think we are fairly aggressive about reintervening on the right ventricle-pulmonary artery conduit. As you know, the Contegra conduit (Medtronics) is not even approved for use in this indication, so we inserted only 2 Contegra homografts in this series, but we have a relatively aggressive institutional stance to conduit replacement. In our experience, homografts in the current era are not particularly predictable.

Dr Ungerleider. I think there are a lot of conduits out there that are not being replaced but are dysfunctional. In the past year, we have been making polytetrafluoroethylene (W.L. Gore \& Associates, Inc, Flagstaff, Ariz) valves. We have altered the technique that Jim Quintessenza has described and are making trileaflet valves. Jim has been making bileaflet polytetrafluoroethylene valves. We are placing these valves in a tube, similar to our modified Ross procedure. We think these may be better than allografts. I do not know, but it just was an interesting number. It caught my attention.

Finally, why did you include the truncus patients in this? I know they are getting AoV replacements. However, because some options are not available to them, they may also tend to obscure and contaminate the data unless they are looked at as a separate group. They cannot get autografts, for example. I am just curious about the thinking of including them.

Dr Fraser. As Dr Khan noted, our goal was to present the worst case scenario for aortic root interventions in our hospital. Notwithstanding the fact that there are multiple other previous series published, we thought that having a snapshot of what we have been doing in our hospital and particularly in the context of counseling families at the time of this difficult decision is important. I find the AoV consults with families one of the most difficult and lengthy consults I have with patients before surgery. Trying to provide them the profile of all-comers and what our experience has been seemed important. Admittedly, the truncus patients are the worst actors in terms of truncal/AoV durability and risk profile. 